\title{
Listeria monocytogenes contamination of finishing pigs: an exploratory epidemiological survey in France
}

\author{
Pierre-Alexandre BELCEIL ${ }^{\mathrm{a} *}$, Claire CHAUVIN ${ }^{\mathrm{a}}$, Marie-Thérèse TOQUIN ${ }^{\mathrm{b}}$, \\ Christelle FABLET ${ }^{\mathrm{a}}$, Yolaine LE NÔTRE ${ }^{\mathrm{b}}$, Gilles SALVAT ${ }^{\mathrm{b}}$, \\ François MADEC ${ }^{\mathrm{a}}$, Philippe FRAVALO ${ }^{\mathrm{b}}$ \\ ${ }^{\text {a }}$ Epidemiology and Quality Assurance in Pig Production Unit, AFSSA, French Agency for Food Safety, \\ Pig and Poultry Veterinary Research Laboratory, Zoopôle, BP 53, 22440 Ploufragan, France \\ $\mathrm{b}$ Hygiene and Quality of Poultry and Pork Product Unit, AFSSA, French Agency for Food Safety, \\ Pig and Poultry Veterinary Research Laboratory, Zoopôle, BP 53, 22440 Ploufragan, France
}

(Received 2 January 2003; accepted 14 April 2003)

\begin{abstract}
Listeria monocytogenes is a foodborne pathogen of major concern for public health in industrialised countries. Since L. monocytogenes carriage by pigs at the herd level could be a primary source for carcass contamination, control measures should be designed to reduce the L. monocytogenes load at the pre-harvest stage. For this purpose, an exploratory analytical survey was carried out in 2000-2001 in 93 French farrow-to-finish pig farms concerning L. monocytogenes contamination in pigs before they left for the slaughterhouse. On each farm, the L. monocytogenes status of a batch of contemporary fattening pigs housed in the same room was assessed on faecal material samples taken by means of gauze swabs wiped on the perianal region of the pigs. Fourteen percent of the batches studied had at least one contaminated sample and were therefore classified as L. monocytogenes contaminated batches. Two logistic regression models were used to assess the association between managerial and hygiene practices and the risk of L. monocytogenes contamination of the batch at the end of the finishing period on the whole data set $(n=93)$ and in the wet feeding farms only $(n=57)$. Wet feeding during the fattening period was identified as a risk factor for $L$. monocytogenes contamination. Risk factors related to the introduction of $L$. monocytogenes in pig facilities were identified for both the general and wet feeding farm data sets. Poor care paid to hygiene on the farms was found to increase the risk of being infected (boots cleaning, change room presence). When the duration of the empty period prior to the introduction of growing pigs was less than one day in the fattening section, the risk of $L$. monocytogenes contamination was significantly increased. For wet feeding farms, a distribution pipeline cleaning procedure including disinfection was found to be associated with a higher risk of contamination than no cleaning or a procedure consisting of rinsing with water only.
\end{abstract}

Listeria monocytogenes / epidemiology / finishing pig / risk factor / wet feeding

\section{INTRODUCTION}

Listeria monocytogenes is a major human bacterial foodborne pathogen. It is of major concern for public health in many industrialised countries. L. monocytogenes is responsible for opportunistic infections especially in vulnerable and immunocompromised subjects, such as new-born infants, pregnant women, cancer or AIDS

\footnotetext{
* Corresponding author: pierre-alexandre.beloeil@agriculture.gouv.fr
} 
patients and the elderly. It may cause meningitis, encephalitis, sepsis, foetal death, prematurity and death. Listeriosis is a serious illness with a high fatality rate (20$30 \%$ ) or with neurological sequelae due to the tropism of Listeria for the central nervous system. In Europe, the annual incidence rate varies from 2 to 15 cases per million inhabitants [33]. In 1997, in the United States, 5 cases per million inhabitants were recorded [15], with a case fatality rate of 20\% [31]. In 1999, 270 cases were recorded by the two French reporting systems, and the annual incidence rate was therefore estimated to be 4.4 cases per million inhabitants in France [18].

Contaminated food has been identified as the main route of infection and is potentially responsible for $99 \%$ of all cases of listeriosis in the United States [31]. A wide range of contaminated foodstuffs, including dairy products, meats, seafood products and other processed food may be vectors of L. monocytogenes. Human listeriosis can occur either as a sporadic disease or as outbreaks. In recent sporadic or epidemic outbreaks occurring in various industrialised countries, certain types of meat products, especially delicatessen pork products, were involved [13, 17, 24, 28, 30, 38]. Three of these outbreaks were pork-related and occurred in France: cooked pork tongue in jelly was involved in 1992 [24], "rillettes" (potted meat made from pork) were involved in 1993 [17] and both of these products were involved in 1999-2000 [13].

It has been hypothesized that the main source of food contamination by L. monocytogenes is live animals [2, 40]. Pig farms have been considered to be a primary source of Listeria found in slaughterhouses [32, $36,40,42]$. Healthy carrier slaughter pigs are thought to have introduced L. monocytogenes contamination into the plant, as demonstrated by the molecular fingerprinting method [16]. It was early suspected that growing pigs were resistant to L. monocytogenes infection [6]. Since then several reports have mentioned that $L$. monocy- togenes is asymptomatically carried by the pigs $[1,5,14,23,26,40,43]$.

A reduction of the L. monocytogenes intestinal carriage rate of pigs at the herd level should reduce the contamination pressure at the slaughterhouse. The risk factors for this intestinal carriage need to be identified in order to design an adequate intervention strategy to reduce $L$. monocytogenes contamination of finishing pigs. To the best of our knowledge, no study has been carried out in order to determine the risk factors for Listeria contamination of pig farms. However, although risk factors have not been specifically identified, the feeding system (wet vs. dry) during the fattening phase is reported as a putative factor that may influence the contamination of pigs [39].

The aim of the present exploratory study was therefore to assess the relationships between certain pig farm characteristics, with a particular emphasis on feeding systems, their related managerial and hygiene practices, and their health status, and L. monocytogenes pig contamination at the end of the finishing period.

\section{MATERIALS AND METHODS}

\subsection{Study design}

This study was carried out from November 2000 to October 2001 and involved 93 French farrow-to-finish pig farms, selected from among those affiliated with 14 farmer organisations and 8 feed companies. To participate in the study, the farms had to be farrow-to-finish operations of the confined intensive type, managed using the batch procedure (weaning of one group of sows on the same day and age-segregated rearing) with an all-in/all-out hygiene policy for farrowing, post-weaning and fattening sections. Farm selection was also based on the farmer's willingness to cooperate.

The epidemiological unit of this study was a batch of contemporary growing pigs 
housed in the same room on each farm. A room is here part of a fattening pig building separated from the adjacent ones by walls and a door, which usually contains 80 to 150 pigs located in 8 to 15 pens. The batches were investigated at the end of the fattening period. Each farm was visited from one to seven days before slaughter. Information on potential risk factors related to Listeria spp. contamination of the batch were gathered by means of questionnaires, measurements and bacteriological laboratory investigations.

Thirty investigators were involved in the survey, corresponding to veterinarians and technicians from the companies involved or from the staff of our laboratory. Prior to data collection, external investigators were met and taught how to carry out the investigations (measurements, environmental sampling, administration of the questionnaire).

A questionnaire was administered by an investigator to each farmer (available upon request). Data concerning the general characteristics of the farm and the premises, biosecurity procedures, feeding systems and the rearing characteristics of the batch followed during the farrowing and postweaning periods were collected (Tab. I). The on-farm technical documents were checked for this purpose. The rearing characteristics and sanitary events occurring during the rearing period were also recorded.

In each room visited, the perianal regions of the pigs were wiped with 5 SODIBOX ${ }^{\circledR}$ swabs (Sodibox, La ForêtFouesnant, France). The SODIBOX ${ }^{\circledR}$ environmental swab is a sterile square piece of cotton cloth $(32 \mathrm{~cm} \times 32 \mathrm{~cm})$ moistened with isotonic saline solution. Each swab was used to wipe three different pigs from a same pen. Five different pens per room were investigated in this way. After use, the swabs soiled with faecal material were placed in a sterile plastic bag.

Cooled samples and questionnaires were sent by the investigators to the French Agency for Food Safety laboratory on the day of collection. Express postal services were used for farms located a long way from the laboratory.

\subsection{Microbiological analyses}

Swabs were analysed for the presence of Listeria spp. Demi Fraser broth $(150 \mathrm{~mL})$ (Oxoid, Basingstoke, UK) were poured directly into each plastic bag with the swab. Samples were blended for 2 min with a stomacher (AES Laboratoire, Combourg, France) and were incubated at $30^{\circ} \mathrm{C}$. After $24 \mathrm{~h}$ of primary enrichment, $0.1 \mathrm{~mL}$ of each culture in demi Fraser broth was subcultured for $48 \mathrm{~h}$ in $10 \mathrm{~mL}$ of Fraser broth tubes at $37{ }^{\circ} \mathrm{C}$ for secondary enrichment. Final demi Fraser broth and final Fraser broth (0.01 mL of each) were both streaked onto PALCAM agar (AES Laboratoire, Combourg, France). PALCAM plates were incubated at $37^{\circ} \mathrm{C}$ for $48 \mathrm{~h}$.

According to the method developed by Chasseignaux et al. [7], $3 \mathrm{~mL}$ of tryptone saline broth were poured onto PALCAM plates presenting presumptive positive colonies. After $1 \mathrm{~min}$ of contact, $0.5 \mathrm{~mL}$ of the resulting homogenised bacterial suspension was tested for L. monocytogenes by the MiniVidasLMO detection kit, as described by the manufacturer (Biomérieux, Marcy l'Étoile, France). The samples that tested positive by MiniVidasLMO ${ }^{\mathrm{TM}}$ were subcultured onto ALOA plates for $24 \mathrm{~h}$ at $37^{\circ} \mathrm{C}$ in order to confirm the species and to carry out biochemical identifications after subculturing on tryptone soya agar with yeast extract (TSAYE, Oxoid) and then on tryptone soya broth with yeast extract (TSBYE, Oxoid).

Presumptive L. monocytogenes colonies on ALOA were subcultured onto TSAYE. One colony with a bluish tinge on TSAYE agar was subcultured in TSBYE for $24 \mathrm{~h}$ at $37{ }^{\circ} \mathrm{C}$. The species were identified by a microtitre plate method. They were tested for catalase, haemolysis and fermentation of D-xylose and L-rhamnose. A CAMP-test was also performed [25]. 
Table I. Summary of items included in the questionnaire used to analyse risk factors for $L$. monocytogenes in finishing pigs in French farrow-to-finish herds. The number of questions per subset is indicated in brackets.

- General items related to the farm

- Farm characteristics $(n=21)$

- Farm staff characteristics

- Size

- Size of sections (farrowing, post-weaning, fattening)

- Location

- Productivity

- Health level

- Biosecurity $(n=30)$

- Access to facilities and surroundings

- Working procedures

- Hygiene procedures (dead pig disposal...)

- Control of wildlife (rodents, insects)

- Acclimatisation phase for replacement gilts (accommodation, duration...)

- Feeding $(n=21)$

- Type of feeding during farrowing, $\mathrm{PW}$ and fattening period

- Water quality

- Feeding and drinking practices (characteristics of the feeding systems used...)

- Hygiene management of feed storage

- Vaccination scheme in sows and growing pigs $(n=6)$

- Items related to the batch studied

- Farrowing phase $(n=26)$

- Characteristics of the farrowing facilities

- Characteristics of the sows

- Health disorders in sows and piglets

- Hygiene procedure

- Cleaning and disinfection procedure

- Post-weaning phase $(n=33)$

- Characteristics of the post-weaning facilities

- Health disorders in piglets

- Hygiene procedure

- Cleaning and disinfection procedure

- Fattening phase ( $n=61)$ [the batch studied was housed in an unique fattening room]

- Characteristics of the fattening room

- Cleaning and disinfection procedures applied before loading the batch

- Feeding management:

- Feed intake (ration)

- Feed acidification

- Cleaning procedure of the liquid feeding system

- Dung management

- Pest control

- Heating

- Sanitary events

- Health management (treatments, vaccination) 


\subsection{Statistical analyses}

The observation unit was the fattening room housing the batch investigated. A batch was declared to be contaminated by Listeria monocytogenes when one or more swab tested positive. The outcome variable, "Batch status", was therefore dichotomous (contaminated batch vs. non-contaminated batch).

Since wet feeding is thought to be a putative risk factor, two analyses were carried out. The first analysis was performed on the complete data set, whereas the second analysis focused on the wet fed batches only. On both data sets, a two-stage statistical procedure was used to assess the relationships between explanatory variables and the L. monocytogenes status of the batch.

In the first stage, a bivariate analysis related the L. monocytogenes status of the batch to each of the explanatory variables. The explanatory variables were previously coded categorically. The number of categories per variable was limited, so that the frequency rates of categories were $>10 \%$. The variables associated (likelihood ratio $\chi^{2}$-test or the Fisher exact test, $P<0.25$ ) with the L. monocytogenes status of the batch were selected first (Tab. II). All bilateral relationships between the possible explanatory variables were checked. For relationships between variables evidencing strong structural collinearity, one of the two variables of interest (the most closely related to the outcome variable) was chosen.

The second stage involved multiple logistic regression models performed (proc LOGISTIC) [37] according to the method described by Hosmer and Lemeshow [21]. These models included variables that passed the first screening step. Manual backward stepwise logistic regression analyses were carried out to select explanatory variables. The contribution of each variable to a model was tested using a likelihood ratio $\chi^{2}$-test [29]. The two logistic regression models were obtained with all factors significant at $P<0.1$. The odds ratios assessed in final models were converted into relative risks according to the method developed by Beaudeau and Fourichon [3].

\section{RESULTS}

\subsection{Risk factors in the population of farms investigated}

Thirteen (14\%) of the 93 batches studied tested positive for L. monocytogenes. In two batches, all five samples tested positive, one batch presented three positive swabs, two batches presented two positive swabs, and all other batches $(n=8)$ had one positive swab.

Three risk factors were significantly associated with $L$. monocytogenes contamination at the end of the rearing period (Tab. III). The risk for L. monocytogenes contamination was increased when wet feed was provided during the fattening period $\left(P<0.1 ; \mathrm{RR}=3.7 ; \mathrm{CI}_{90 \%}=1.1\right.$, 13.7). When the duration of the "empty" post-weaning room period prior to the introduction of the piglets was less than or equal to 1 day, the risk of being contaminated by L. monocytogenes at the end of the rearing period was significantly increased $\left(P<0.1 ; \mathrm{RR}=2.8 ; \mathrm{CI}_{90 \%}=1.1,6.7\right)$. The risk of being contaminated was higher $(P<$ $0.05, \mathrm{RR}=3.8 ; \mathrm{CI}_{90 \%}=1.4,11.4$ ) when low or no care was taken to cleaning and the boots of the workers were disinfected once a week or less.

\subsection{Risk factors in the subpopulation of wet fed farms investigated}

Among the 57 wet fed batches, 11 (19\%) tested positive for L. monocytogenes. Two risk factors were significantly associated with $L$. monocytogenes contamination at the end of the rearing period (Tab. IV). The absence of a change room at the entrance of the pig rearing facilities was a risk factor $\left(P<0.1 ; \mathrm{RR}=5.8 ; \mathrm{CI}_{90 \%}=1.2,35.1\right)$. Cleaning and disinfecting the pipeline with 
Table II. Definition and distribution of explanatory variables selected after bivariate analysis of L. monocytogenes shedding by market-age pigs (quantitative variables were divided into categories) (farrow-to-finish pig herds, France, 2000-2001).

\begin{tabular}{|c|c|c|c|}
\hline Definition of variables & $\begin{array}{l}\% \text { of batche } \\
\text { per level }\end{array}$ & $\begin{array}{l}\% \text { of Listeria posi- } \\
\text { tive batches per level }\end{array}$ & $P$ \\
\hline \multicolumn{4}{|l|}{ All the 93 farms studied } \\
\hline Well-kept surroundings (enclosed, weeded) ${ }^{\mathrm{a}}$ & & & 0.22 \\
\hline .Yes & 63.4 & 10.2 & \\
\hline . No & 36.6 & 20.6 & \\
\hline Frequency of boot disinfection ${ }^{\mathrm{a}}$ & & & 0.01 \\
\hline More than once a week & 55.9 & 5.8 & \\
\hline Once a week or less & 44.1 & 24.4 & \\
\hline \multicolumn{3}{|l|}{$\begin{array}{l}\text { Duration of the "empty and clean" period prior to stocking the } \\
\text { fattening room with the pigs investigated" }\end{array}$} & 0.04 \\
\hline One day or less & 17.2 & 31.3 & \\
\hline More than one day & 82.8 & 10.4 & \\
\hline Frequency of knacker's truck collection ${ }^{\mathrm{a}}$ & & & 0.05 \\
\hline twice a week or less & 12.9 & 0 & \\
\hline between three and five times a week & 62.4 & 12.1 & \\
\hline more than five times a week & 24.7 & 26.1 & \\
\hline \multicolumn{3}{|l|}{ Number of sows in the (farrow-to-finish) pig farm } & 0.03 \\
\hline.$\leq 160$ & 58.1 & 7.4 & \\
\hline.$>160$ & 41.9 & 23.1 & \\
\hline \multicolumn{3}{|l|}{ Number of sows per worker } & 0.04 \\
\hline.$\leq 80$ & 48.4 & 6.7 & \\
\hline.$>80$ & 51.6 & 20.8 & \\
\hline Acidification of feed during the fattening period ${ }^{\mathrm{a}}$ & & & 0.09 \\
\hline .Yes & 25.8 & 25 & \\
\hline . No & 74.2 & 10.1 & \\
\hline \multicolumn{3}{|l|}{ Type of feeding during the fattening period ${ }^{a}$} & 0.05 \\
\hline . Dry & 38.7 & 5.6 & \\
\hline . Wet & 61.3 & 19.3 & \\
\hline \multicolumn{4}{|l|}{ Subgroup of the 57 wet feeding farms } \\
\hline Well-kept surroundings (enclosed, weeded) & & & 0.09 \\
\hline .Yes & 61.4 & 11.4 & \\
\hline . No & 38.6 & 31.8 & \\
\hline \multicolumn{3}{|l|}{ Presence of a change room at the entrance to the facilities ${ }^{a}$} & 0.04 \\
\hline .Yes & 36.8 & 4.8 & \\
\hline \multirow{2}{*}{\multicolumn{3}{|c|}{ Number of pigs in the fattening room ${ }^{\mathrm{a}}$}} & \\
\hline & & & 0.02 \\
\hline.$<120$ & 43.9 & 4 & \\
\hline.$\geq 120$ & 56.1 & 31.3 & \\
\hline Antibiotic treatment during the fattening phase ${ }^{\mathrm{a}}$ & & & 0.15 \\
\hline .Yes & 28.1 & 6.3 & \\
\hline \multirow{2}{*}{\multicolumn{3}{|c|}{ Dejection observed in the feeding systems during the fattening phase $\mathrm{a}^{\mathrm{a}}$}} & \\
\hline & & & 0.18 \\
\hline Yes & 45.6 & 26.9 & \\
\hline . No & 54.4 & 12.9 & \\
\hline \multicolumn{3}{|l|}{ Cleaning and disinfection of the pipeline ${ }^{\mathrm{a}}$} & 0.01 \\
\hline With water and disinfectant more than once a month & 17.5 & 30.0 & \\
\hline With water and disinfectant once a month or less & 26.3 & 40.0 & \\
\hline . With water & 10.5 & 16.7 & \\
\hline & 45.6 & 3.9 & \\
\hline \multicolumn{3}{|l|}{ Length of feeding system pipeline ${ }^{\mathrm{a}}$} & 0.17 \\
\hline$<200 \mathrm{~m}$ & 57.9 & 12.1 & \\
\hline.$\geq 200 \mathrm{~m}$ & 42.1 & 29.2 & \\
\hline
\end{tabular}

a Variable included in the screening step for inclusion in the logistic model $(P<0.25)$. 
Table III. The final logistic regression model for risk factors for Listeria shedding of French finishing pigs at market age (93 farrow-to-finish pig herds, France, 2000-2001).

\begin{tabular}{|c|c|c|c|c|c|c|}
\hline \multirow{2}{*}{ Variables } & \multicolumn{2}{|c|}{ Number of batches } & \multicolumn{4}{|c|}{ Logistic regression model ${ }^{\mathrm{a}}$} \\
\hline & Positive & Negative & OR & $90 \% \mathrm{CI}$ & $\mathrm{RR}^{\mathrm{b}}$ & $90 \% \mathrm{CI}$ \\
\hline \multicolumn{7}{|c|}{$\begin{array}{l}\text { Type of feeding during the fattening } \\
\text { period }\end{array}$} \\
\hline . Dry & 2 & 34 & 1.0 & - & 1 & - \\
\hline . Wet & 11 & 46 & 4.4 & $1.1-17.2$ & 3.7 & $1.1-13.7$ \\
\hline \multicolumn{7}{|c|}{$\begin{array}{l}\text { Duration of "empty and clean" period } \\
\text { prior to stocking the fattening room } \\
\text { with the pigs investigated }\end{array}$} \\
\hline More than one day & 8 & 69 & 1.0 & - & 1 & - \\
\hline One day or less & 5 & 11 & 3.5 & $1.4-11.8$ & 2.8 & $1.1-6.7$ \\
\hline \multicolumn{7}{|l|}{ Frequency of boot disinfection } \\
\hline More than once a week & 3 & 49 & 1.0 & - & 1 & - \\
\hline Once a week or less & 10 & 31 & 4.7 & $1.4-15.6$ & 3.8 & $1.4-11.4$ \\
\hline
\end{tabular}

a Intercept $=-4.08$, Model deviance $=3.8$ (d.f. $=4, P=0.42$ ).

$\mathrm{b}$ Relative risks obtained according to Beaudeau and Fourichon [3].

Table IV. The final logistic regression model for risk factors for Listeria shedding of French wet fed finishing pigs at market age (57 farrow-to-finish pig herds, France, 2000-2001).

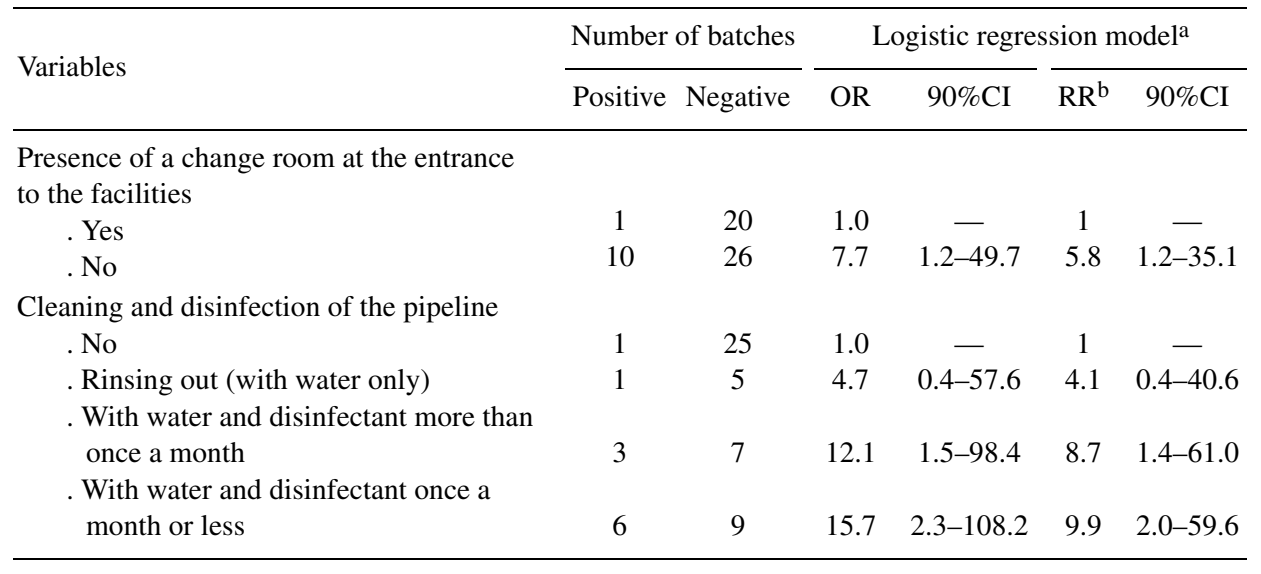

a Intercept $=-4.8$, model deviance $=1.87$ (d.f. $=3, P=0.6$ ).

$\mathrm{b}$ Relative risks obtained according to Beaudeau and Fourichon [3].

water and disinfectant were practices significantly at risk compared to no cleaning. The estimated relative risk for L. monocytogenes contamination when cleaning and disinfection was performed more than once a month $\left(\mathrm{RR}=8.7 ; \mathrm{CI}_{90 \%}=1.4,61.0\right)$ was lower than the estimated relative risk for L. monocytogenes contamination when cleaning and disinfection was performed once a month or less $\left(\mathrm{RR}=9.9 ; \mathrm{CI}_{90 \%}=\right.$ 2.0, 59.6). However, rinsing the pipeline with water only was not associated with a significantly greater risk than never cleaning the pipeline. 


\section{DISCUSSION}

Only a very few studies have dealt with the pig herd L. monocytogenes contamination despite the fact that $L$. monocytogenes contamination of pork products is of great concern for public health. In the literature, the detection of the L. monocytogenes pig batch status has been more frequently described by means of samples taken at the slaughterhouse. Sampling methods were either individual coprology [1, 14, 40, 42], tonsillar swabbing [26] or skin swabbing [11] on a sample of pigs. The ability of the skin swabbing method to detect L. monocytogenes contamination of pigs has already been demonstrated [11]. It also presents the advantage of not requiring animal contention for sampling and is therefore less timeconsuming than coprology. These elements were thought to be important in view of the fact that voluntary investigators from farmer organisations or feed companies participated free of charge in this study.

The sensitivity and specificity of the detection method of L. monocytogenes used in this study are not known but can be considered imperfect. The sensitivity is certainly lower than $99 \%$ due to the fact that all the pens of a fattening room were not investigated and that there was limited sensitivity of the microbiological isolation method. Some of the rooms which tested negative may have been falsely negative and therefore they may have been misclassified. Nevertheless, the specificity of the detection method can be estimated to $99 \%$ according to Christensen and Gardner [8]. Therefore, the rate of $L$. monocytogenes positive batches estimated in this study may be underestimated.

The study designs of previously published studies concerning L. monocytogenes contamination of pigs mainly investigated individual carriage rates at the slaughterhouse. The percentage of L. monocytogenes carriers reported by authors are $0.8 \%(46 / 5975)$ [23], $1.7 \%$ (3/172) [40], $2.4 \%(44 / 1849)$ [26], 3\% (3/97) [5], 5.9\% (2/34) [43] and $16 \%(4 / 25)$ [42]. Since the numbers of different herds involved in these studies were not specified, it is therefore difficult to compare these data with the results of our study, conducted at the batch level. One study conducted at a group-level reported $27.5 \%$ of positive batches [11].

The difference between the observed positive rates reported above could be due to differences in the study design and improvement of microbiological isolation methods since the studies by Skovgaard and Norrung in 1989 [40] and Buncic in 1991 [5]. No standard method has been developed to detect L. monocytogenes in highly contaminated environmental samples such as those from rearing pig facilities. Isolation agars classically used, such as Oxford or Palcam, do not allow the distinction based on the morphological appearance of colonies between L. monocytogenes and other species of Listeria, such as L. innocua, which has also been reported in pig samples [5]. Moreover, the growth advantage of L. innocua and the production of inhibitory compounds by $L$. innocua may both result in a high L. innocua / L. monocytogenes ratio in the incubated broth [10]. Random selection of ten typical Listeria colonies from Palcam agar plates would therefore not lead to a high probability of L. monocytogenes detection. The method developed by Chasseignaux et al. [7] improved the sensitivity of L. monocytogenes isolation in the present study. Sampling performed at the slaughterhouse [11] could also be influenced by the effect of the pre-harvest process, which has been shown to increase the Salmonella contamination rate of pigs between the farm and the slaughterhouse [22]. Differences in the proportion of wet and dry fed pigs studied could also explain differences in positive percentages reported in the literature and in the present study.

Wet feed is distributed to the pigs by a liquid feeding system through a pipeline whose microbiological ecology may influence wet feed contamination. Technical studies carried out on liquid feeding systems have shown that liquid feeding systems are 
biologically active by means of feed residue layers and biofilms accumulated on the internal surface of the pipeline and valves $[20,35]$. In the present study, wet feeding was identified to be a risk factor for L. monocytogenes contamination of a finishing batch. Wet feed has been previously considered to influence pig contamination [40]. It has also been reported [39] that L. monocytogenes can be isolated from $2 \%$ of the faeces of dry fed animals, versus $25 \%$ to $50 \%$ of the faeces of wet fed animals. An explanation proposed by Skovgaard [39] for these different results of pig faeces contamination was a lower rate of Listeria in dry feed than in wet feed. The different contamination rates between dry vs. wet feed could be explained by the different types of treatment used for these two kinds of feed. Among other things, the pelleting process involves heat treatment, a process not applied to meal. This heat treatment could influence Listeria contamination of the pellets.

The model adjusted to the data obtained from the wet fed subgroup supported a role of feed residue layers and biofilms. One of the two risk factors identified was related to the liquid feeding system and more precisely to the pipeline cleaning and disinfection procedure. Rinsing the pipeline with water only was not associated with a significantly greater risk than never cleaning the pipeline. Moreover, using disinfectant presented a greater risk than never cleaning the pipeline. Two hypotheses can be raised to explain this paradoxical result. On the one hand, Skovgaard [39] supposed that feed residue layers might contain $L$. monocytogenes. These residue layers and biofilms would be more likely to be suspended by the cleaning and disinfection procedure. The layers and biofilms suspended would also be more contaminated by Listeria when the frequency of cleaning and disinfection is low (less than twice a month). On the other hand, Hansen and Mortensen [20] and Royer et al. [35] reported that feed residue layers and biofilms were normally dominated by lactic acid bacteria and yeast.
Taking into account the antilisterial activity of some lactobacillus species due to bacteriocin-like substances [34] and the effect of lactic acid on Listeria growth [9], internal biofilms of the pipeline would have a protective action against Listeria spp. The alteration of the biofilms by cleaning and disinfection, observed by Hansen and Mortensen [20] and Royer et al. [35], would facilitate pig Listeria spp. contamination. The cleaning and disinfection effect observed on the lactic and coliform flora resulted in a decrease of the lactic flora with an increase of coliform bacteria counts during the first days and it took 5 to 7 days to return to the baseline situation [20,35]. Regardless of the mechanism of L. monocytogenes contamination involved, alteration of the microbiological equilibrium of the pipeline appears to be a major issue involved in cleaning and disinfection. Further studies must be carried out to improve the knowledge of the pipeline microbiological ecology and to investigate the role of the pipeline as a vector of L. monocytogenes via the feed residue layer and biofilms and to determine good hygiene practices of current liquid feeding systems: cleaning and disinfection procedure, frequency, etc. in order to control this source of L. monocytogenes.

The other risk factors identified in both models concerned the general hygiene on the pig farm. In the entire data set, low or no attention paid to disinfection of the boots of the farm staff was a risk factor for $L$. monocytogenes contamination. This result is consistent with that obtained on the wet feed subgroup, which is related to the lack of a change room at the entrance of the pig facilities. In the entire data set, a very short duration of the "empty and clean" period prior to stocking the fattening room was also found as a risk factor for L. monocytogenes contamination at the end of the fattening period. Taken together, these factors related to general hygiene tend to suggest a link with a soil source of contamination of pig facilities and emphasize a possible 
contamination cycle between successive batches. L. monocytogenes has been previously detected in the soil [44] and on farm environmental samples [14]. Residual faecal contamination after cleaning and disinfection of the fattening pens could promote transmission of L. monocytogenes from one batch to the next.

Due to imperfections of the detection method, misclassification of batches based on outcome may have occurred. Misclassification may be assumed to be non-differential since the exposition to potential risk factors is not affected by the L. monocytogenes contamination status, unknown to the farmer. If misclassification is non-differential, the unadjusted estimator of OR systematically underestimates the true OR [19]. Therefore, additional risk factors could have been identified with a better detection method and/or with a larger sample of farms studied.

The risk factors were identified on a sample of farms applying the usual management practices, since change rooms are not systematically available in pig facilities and the feeding system procedures observed in a recent study [35] were very similar to those reported in the present study. The pre-eminence $(61.3 \%)$ of wet feeding encountered in this farm sample is consistent with national practices. It is therefore very important to more accurately determine the relationship between wet feeding and L. monocytogenes, since an important part of pork production is potentially exposed to this risk factor. Wet feeding is also involved in the control of another foodborne pathogen: Salmonella enterica. However, the increasing risk for L. monocytogenes contamination of finishing pigs due to wet feeding during the fattening period contrasts with the protective effect of wet feeding on Salmonella enterica contamination of finishing pigs. Salmonella infection has been shown to be more prevalent in dry-fed herds than in wet-fed herds $[4,12,27,41]$.

\section{ACKNOWLEDGEMENTS}

The authors gratefully acknowledge the pig farmers, their organisations, the feed companies and the investigators for their active co-operation in this project. This project was supported financially by the Food Safety Department of the French Ministry of Agriculture, Food, Fisheries and Rural Affairs.

\section{REFERENCES}

[1] Adesiyun A.A., Krishnan C., Occurrence of Yersinia enterocolitica O:3, Listeria monocytogenes $\mathrm{O}: 4$ and thermophilic Campylobacter spp. in slaughter pigs and carcasses in Trinidad, Food Microbiol. 12 (1995) 99-107.

[2] Autio T., Säteri T., Frederiksson-Ahomaa M., Rahkio M., Lundén J., Korkeala H., Listeria monocytogenes contamination pattern in pig slaughterhouses, J. Food Prot. 23 (2000) 1438-1442.

[3] Beaudeau F., Fourichon C., Estimating relative risk of disease from output of logistic regression when the disease is not rare, Prev. Vet. Med. 36 (1998) 243-256.

[4] Belœil P-A., Eveno E., Gerault P., Fravalo P., Rose V., Rose N., Madec F., An exploratory study about contamination of pens of finishing pigs by ubiquitous Salmonella, in: Proceedings of the Third International Symposium of the Epidemiology and Control of Salmonella in Pork, Washington, D.C., USA, 5-7 August 1999, pp. 101-105.

[5] Buncic S., The incidence of Listeria monocytogenes in slaughtered animals, in meat and in meat products in Yugoslavia, Int. J. Food Microbiol. 12 (1991) 173-180.

[6] Busch R.H., Barnes D.M., Sauter J.H., Pathogenesis and pathologic changes of experimentally induced listeriosis in new born pigs, Am. J. Vet. Res. 32 (1971) 1313-1320.

[7] Chasseignaux E., Michel Y., Toquin M.T., Ermel G., Salvat G., Colin P., Comparison of two rapid methods for the detection of Listeria monocytogenes with a standard procedure in naturally contaminated environments of raw poultry processing, J. Rapid Methods Autom. Microbiol. 7 (1999) 147-153.

[8] Christensen J., Gardner I.A., Herd-level interpretation of test results for epidemiologic studies of animal diseases, Prev. Vet. Med. 45 (2000) 83-106.

[9] Conner D.E., Scott V.N., Bernard D.T., Growth, inhibition and survival of Listeria 
monocytogenes as affected by acidic conditions, J. Food Prot. 53 (1990) 652-655.

[10] Cornu M., Kalmokoff M., Flandrois J.P., Modelling the competitive growth of Listeria monocytogenes and Listeria innocua in enrichment broths, Int. J. Food Microbiol. 73 (2002) 261-274.

[11] Corrégé I., Incidence des opérations d'abattage et de découpe des porcs sur la contamination par Listeria monocytogenes, Viandes et Produits Carnés 18 (1997) 275-282.

[12] Dahl J., Cross-sectional epidemiological analysis of the relations between different herd factors and Salmonella positivity, Epidémiol. Santé Anim. 31-32 (1997) 04.23.1-04.23.3.

[13] de Valk H., Vaillant V., Jacquet C., Rocourt J., Lequerrec F., Stainer F., Quelquejeu N., Pierre O., Pierre V., Desenclos J.-C., Goulet V., Two consecutive nationwide outbreaks of listeriosis in France, October 1999-February 2000, Am. J. Epidemiol. 154 (2001) 944950.

[14] Fenlon D.R., Wilson J., Donachie W., The incidence and level of Listeria monocytogenes contamination of food sources at primary production and initial processing, $\mathrm{J}$. Appl. Bacteriol. 81 (1996) 641-650.

[15] FSIS, Food safety and inspection service revised action plan for control of Listeria monocytogenes for the prevention of foodborne listeriosis. Food Safety and Inspection Service, News and Information, May 2000, United States Department of Agriculture, Washington.

[16] Giovannacci I., Ragimbeau C., Queguiner S., Salvat G., Vendeuvre J.-L., Carlier V., Ermel G., Listeria monocytogenes in pork slaughtering and cutting plants use of RAPD, PFGE and PCR-REA for tracing and molecular epidemiology, Int. J. Food Microbiol. 53 (1999) 127-140.

[17] Goulet V., Rocourt J., Rebiere I., Jacquet C., Moyse C., Dehaumont P., Salvat G., Veit P., Listeriosis outbreak associated with the consumption of rillettes in France, J. Infect. Dis. 177 (1998) 155-160.

[18] Goulet V., Jacquet C., Laurent E., Rocourt J., Vaillant V., de Valk H., La surveillance de la listériose humaine en France en 1999, Bull. Epidémiol. Hebd. 34 (2001) 161-165.

[19] Greiner M., Gardner I.A., Application of diagnostic tests in veterinary epidemiologic studies, Prev. Vet. Med. 45 (2000) 43-59.

[20] Hansen I.T., Mortensen B., Pipe-cleaners beware !, Pig International 19 (1989) 8-10.
[21] Hosmer D.W., Lemeshow S., Applied Logistic regression, Wiley, New York, 1989, p. 307.

[22] Hurd H.S., McKean J.D., Griffith R.W., Wesley I.V., Rostagno M.H., Salmonella enterica infections in market swine with and without transport and holding, Appl. Environ. Microbiol. 68 (2002) 2376-2381.

[23] Iida T., Kanzaki M., Nakama A., Kokubo Y., Maruyama T., Kaneuchi C., Detection of Listeria monocytogenes in humans, animals and foods, J. Vet. Med. Sci. 60 (1998) 13411343.

[24] Jacquet C., Catimel B., Brosch R., Buchrieser C., Dehaumont P., Goulet V., Lepoutre A., Veit P., Rocourt J., Investigations related to the epidemic strain involved in the French listeriosis outbreak in 1992, Appl. Environ. Microbiol. 57 (1995) 2109-2113.

[25] Jones D., Seeliger H.P.R., Listeria, in Balows A., Trüper H.G., Dworkin M., Harder W., Schleifer K.H. (Eds.), The prokaryotes. A handbook on the biology of bacteria: ecophysiology, isolation, identification, applications, Vol. 2, Second edition, Springer-Verlag, 1995.

[26] Kanuganti S.R., Wesley I.V., Reddy P.G., McKean J., Hurd H.S., Detection of Listeria monocytogenes in pigs and pork, J. Food Prot. 65 (2002) 1470-1474.

[27] Kranker S., Dahl J., Wingstrand A., Bacteriological and serological examination and risk factor analysis of Salmonella occurrence in sow herds, including risk factors for high Salmonella seroprevalence in receiver finishing herds, Berl. Munch. Tierarztl. Woschr. 114 (2001) 350-352.

[28] Loncarevic S., Danielsson-Tham M.L., Martensson L., Ringner A., Runehagen A., Tham W., A case of foodborne listeriosis in Sweden, Lett. Appl. Microbiol. 24 (1997) 65-68.

[29] McCullagh P., Nelder J.A., Log-likelihood for binomial data, in: Chapman and Hall (Eds.), Generalized Models, Second edition, London, 1989, pp. 114-119.

[30] McLauchlin J., Hall S.M., Velani S.K., Gilbert R.J., Human listeriosis and pate: a possible association, Br. Med. J. 303 (1991) 773-775.

[31] Mead S.M., Slutsker L., Dietz V., McCaig L.F., Bresee J.S., Shapiro C., Griffin P.M., Tauxe R.V., Food-related illness and death in the United States, Emerg. Infect. Dis. 5 (1999) 607-625.

[32] Nesbakken T., Nerbrink E., Rotterud O.J., Borch E., Reduction of Yersinia enterocolitica and Listeria spp. on pig carcasses by 
enclosure of the rectum during slaughter, Int. J. Food Microbiol. 23 (1994) 197-208.

[33] Rocourt J., Bille J., Foodborne listeriosis, World Health Stat. Q. 50 (1997) 67-73.

[34] Ross R.P., Morgan S., Hill C., Preservation and fermentation: past, present and future, Int. J. Food Microbiol. 79 (2002) 3-16.

[35] Royer E., Moundy G., Albar J., Martineau G.P., Evaluations quantitatives de l'hygiène des différents maillons des machines à soupe, in: Journée "de la démarche hygiène à la biosécurité", Ploufragan, France, 24 avril 2002, pp. 39-53.

[36] Salvat G., Toquin M.T., Michel Y., Colin P., Control of Listeria monocytogenes in the delicatessen industries: the lessons of a listeriosis outbreak in France, Int. J. Food Microbiol. 25 (1995) 75-81.

[37] SAS Institute Inc., SAS/STAT User's Guide, version 8. SAS Institute, Cary, NC, 2001.

[38] Sim J., Hood D., Finnie L., Wilson M., Graham C., Brett M., Hudson J.A., Series of incidences of Listeria monocytogenes noninvasive febrile gastroenteritis involving ready-to-eat meats, Lett. Appl. Microbiol. 35 (2002) 409-413.

[39] Skovgaard N., The impact of the prevalence of Listeria monocytogenes in the environ- ment on meat and milk hygiene, Microbiol. Aliment. Nutr. 8 (1990) 15-20.

[40] Skovgaard N., Nørrung B., The incidence of Listeria spp. in faeces of Danish pigs and in minced pork meat, Int. J. Food Microbiol. 8 (1989) 59-63

[41] van der Wolf P.J., Bongers J.H., Elbers A.R., Franssen F.M., Hunneman W.A., van Exsel A.C., Tielen M.J., Salmonella infections in finishing pigs in The Netherlands: bacteriological herd prevalence, serogroup and antibiotic resistance of isolates and risk factors for infection, Vet. Microbiol. 67 (1999) 263275.

[42] van Renterghem B., Huysman F., Rygole R., Verstraete W., Detection and prevalence of Listeria monocytogenes in the agricultural ecosystem, J. Appl. Bacteriol. 71 (1991) 211-217.

[43] Weber A., Potel J., Schafer-Schmidt R., Prell A., Datzmann C., Studies on the occurrence of Listeria monocytogenes in faecal samples of domestic and companion animals, Zentralbl. Hyg. Umweltmed. 198 (1995) 117123 (in German).

[44] Weis J., Seeliger H.P.R., Incidence of Listeria monocytogenes in nature, Appl. Microbiol. 5 (1975) 29-32. 